\title{
Pensamiento Burgués, en la Poesía de Luis Benjamín Cisneros*
}

\begin{abstract}
Q UrzÁ fuera la aureola divinal que los panegiristas atribuyeron a los anacoretas de la Edad Media, y que la credulidad del pueblo llevó de uno a otro lugar y de un tiempo a otro. Quizá fuera aquella ideal soledad de los místicos, que gustaban apartarse de las ficciones cortesanas y los desvelos del espíritu práctico, para gustar la apacible sencillez de la vida campesina y disfrutar el armonioso concierto de la naturaleza. O quizás fuera la respuesta al intenso y dilatado influjo que Rousseau ejerciera en la formación intelectual de los románticos, idealizando el pasado y justificando las tendencias igualitarias de los hombres laboriosos. Lo cierto es que el ciudadano añora los encantos anunciados por las dilatadas líneas del horizonte. Entre las callejas bulliciosas de su ciudad, y bajo la presión de severas ordenanzas y convenciones, anhela llegar hasta la sombra que generosamente prodigan los árboles adornados con florescencias odorantes, y piensa que las gentes no obedecen allí otro código que el de la fraternidad y la buena fe. Para el empresario y el comerciante, que en épocas ya antañonas superaron con su celo el cansancio, las desconcertadas diatribas del clero y los desmanes de una nobleza derrochadora y engreída, el campo era refugio contra las asechanzas de la envidia. E1 artesano, sobrecogido por la pugnacidad y la previsión de los empresarios, y deslumbrado por el insolente boato de la aristocracia, aspiraba a un goce que no le exigiese esfuerzos febricitantes ni lo expusiese a los excesos de la pasión, y veía en el campo la medida del equilibrio y el sosiego. Ante la contemplación del filósofo y el hombre de letras, que apreciaban los desniveles de la moral y la educación como injustos efectos de los privilegios, el campo alentaba la confianza en el triunfo
\end{abstract}


final de la verdad y la sabiduría. $Y$ a la muchedumbre anónima, humillada y sin fortuna, el campo ofrecía tarea noble y pan seguro. Por esos nuevos tipos de hombre surgidos en la ciudad, por el burgués, habla el eminente Francisco de Quevedo cuando censura a los cortesanos porque en forma insensata "desprecia el honor al que trabaja"; cuando ironiza a costa de la nobleza decadente, cuyos individuos se arrullaban con los nombres de sus antepasados, sin alcanzar a ser "sucesores, sino apodos" de aquéllos; y cuando estima que "en las cabañas / y debajo del cielo / los ásperos villanos gozan del sueño que desprecian los avaros". Y por algo había de ser a una pastora, a quien Tirso de Molina atribuyese su denuesto contra la depravación de El burlador de Sevilla: "la desvergüenza en España/se ha hecho caballería". Porque el aldeano honesto y sobrio concebia la ciudad como un centro donde las tentaciones malignas oscurecían las virtudes del hombre, e imaginaba que las fastuosas costumbres de los señores eran el instrumento de su seductora atracción; y coincidía indirectamente con el burgués, rebelde a la autoridad y las relaciones sociales tradicionales, confiado únicamente en su experiencia y los resultados de su acción, y que, en conflicto con las trabas que a sus propósitos oponían los privilegios que su razón no hallaba justos, se orientaba hacia el campo, en su afán por descubrir "el origen de las desigualdades entre los hombres".

A la manera burguesa, aunque tenuemente ya, porque su definitivo tramonto la alejaba del encono, Luis Benjamín Cisneros* insinuó los caracteres de la aristocracia decadente que durante tres siglos dominó el Perú en nombre de extraño monarca. La concibe como "vejez vana/que invoca la experiencia/para cubrir sus vicios / y hollar la juventud". Y cuando recuerda la gesta de la emancipación nacional, su mente finge el alzamiento de Lima contra la corrupción que la ahogaba, es decir, el alzamiento de "la burguesía contra esa aristocracia senil:

La reina del contento y los placeres sintió de sus destinos el despecho, y despierta a la voz de sus deberes el patrio sentimiento ardió en su pecho; dejó los goces de enervados seres y abandonando del placer el lecho, en son de guerra a combatir se alzaba e "Independencia y Libertad" gritaba. 
Lima era entonces cual Minerva armada bajo radiante clámide de estrellas y era su juventud de alma esforzada, sus mujeres purísimas y bellas.

¡Oh! las madres buscaban una espada que darles a sus hijos, y si ante ellas no hacía el hijo de heroísmo alarde, gritaban con horror: "Es un cobarde".

(El pabellón peruano, 1855)

Y cuando la paz rubricó la conquista de la libertad, el poeta aparta de la ciudad placentera su mirada, y prefiere atribuir apariencia de felicidad campesina a la nueva forma de vida:

El sol daba su esplendor

a sus mil bosques de flores,

y sus dulces trovadores

alzaban cantos de amor.

La aurora se levantaba

del porvenir; en su cielo

iba a remontar el vuelo

$\mathrm{y}$ el iris su cielo ornaba.

Satisfecho el labrador

tras jornada fatigosa,

en el sero de su esposa

soñaba sueños de amor.

(El pabellón peruano, 1855)

Pero los años han sedimentado sus efectos sobre la conciencia de aquellos hombres y el poeta sorprende contornos muy distintos en su conducta, despojada de sus alcances nacionales y de sus rasgos heroicos:

¡Oh Lima, Lima! ¿Tu ardorosa alma

es foco aún de noblë patriotismo,

o acaso estás en vergonzosa calma

y te aletarga estúpido egoísmo?

¡Qué! ¿Ya no anhelas la guerrera palma?

¿Tu juventud no aspira al heroísmo, entregada tan sólo a los placeres

y a la gracia y beldad de tus mujeres?

(El pabeltón peruano, 1856) 
Duele a Luis Benjamin Cisneros el sentido de esta transición, porque la estima contraria al destino descrito por los forjadores de 1a independencia nacional. Cree que la patria libre debe aplicarse al trabajo para realizar las ilusiones alentadas por el programa de la independencia nacional. Cree que es necesario marchar hacia el bien y la belleza, para llevar la dicha hacia el pueblo. Y, consecuentemente, repudia el egoísmo que conduce hacia una epicúrea concepción de la vida:

Pasear por el portal; el horizonte contemplar desde el puente, al aura leda. Ir a la falda del cercano monte. a gozar de la plácida alameda.

En el teatro, después, guste o atonte, aplaudir una voz que al cisne exceda... iInclinemos la frente envilecida! Beber, gozar, reír... i Esa es la vida!

(Desconsuelo, 1858)

¿Acaso debe atribuirse esta voz denunciatoria a una mayor o menor colisión entre los intereses del poeta y la conducta social de la burguesía? ¿O ha de creerse que en ella se desahoga un transitorio antagonismo? Nada de eso. Luis Benjamín Cisneros lanza la voz cálida y generosa de la juventud, e invoca en su pensamiento el halagüeño porvenir que debían franquearle al país los hábitos viriles. Pero lo hiere el visible contraste entre la realidad y los anhelos promovidos por la independencia nacional, afianzándolo en una posición netamente burguesa. No sólo por su concepto del mundo, sino por su adhesión al indivdualismo y los prejuicios propios de la clase mencionada. Así to hace saber, cuando informa acerca de la incomprensión opuesta al sentimiento de solidaridad que lo moviera a vindicar la honra de un amigo injustamente calumniado:

Mi noble afán, con rudo menosprecio, riendo vió la sociedad en poco, iy el mundo, madre, me ha llamado necio! iY el mundo, madre, me ha llamado loco! ¡Loco! y yo sana tal acción aprecio. ¡Necio! y aquí de mi conciencia el foco me dice que hice bien... iOh, madre mía! ¿E1 bien es nal sobre la tierra impía? 
Fuí fiel a la amistad y se indignaron; defendí la virtud, y me agredieron; dije lo que sentía, y me befaron; hablé con humildad, y me ofendieron; y nada de esto, madre, contemplaron; con los malos después me confundieron; pero no guardo, en $\mathrm{mi}$ dolor, encono $\mathrm{y}$, como tú lo harías, los perdono.

(De mi álbum íntimo, 1858)

Claramente afluye en tal actitud la influencia de la moral cristiana; pero el poeta no persiste en su seguimiento, porque más acentuada es en su adhesión a las normas de conducta de la burguesía, y parece absurdo que alguien intente quebrantar el cómodo individualismo que bajo su imperio señorea en la vida. $\mathrm{Y}$ doblegado, aunque sin ocultar su pesadumbre, decide:

iLos nobles sentimientos que han formado

hasta hoy mi juventud, no más aliente!

Sin porvenir, sin esperanza alguna

morirán como un ágtrila en su cuna.

(De mi álbum intimo, 1858)

-Así fué, en cuanto los sentimientos podían conducir hacia un apostolado de justicia, o hacia la solidaridad en la defensa y la revalidación de los ideales que determinaron la independencia nacional. $\mathrm{Ni}$ superior, ni ajeno a su época, Luis Benjamín Cisneros adopta entonces, como cauce de sus actos, la satisfacción de sus objetivos individuales. $Y$, tras esta asunción de la moral imperante, se allana el camino por transitar. El horizonte se aproxima hasta el límite del gozo y la vanidad personales. Luego, los pequeños conflictos de la intimidad afectan valor desmesurado, se convierten en pauta para la apreciación de lo universal y lo inmarcesible. Alienta "aspiraciones cultas que alzan el pensamiento sobre el común nivel de los mortales", porque su individualismo se proyecta ya sobre el mundo. $Y$ hacia el viejo continente lleva sus pasos

no la ilusión ligera

que engendraron la sangre y los deseos

en frívolo mancebo a quien la vida

sólo a gozar convida

fiestas y devaneos; 
no la exaltada, loca fantasía que inflamaron las vivas narraciones o la lectura amena del que otros pueblos recorrido había; no la escasez de pan en la pobreza de humilde hogar honrado, causa crüel de la mortal tristeza del padre desdichado, y que obligando al hijo a abandonar sus lares lo impele en pos de próspera fortuna más allá de los mares; no la viva esperanza ni el prudente cuidado que a extrañas tierras guia al que confió a la nave su tesoro de variada, valiosa mercancía, en sed de lucro y ambición de oro; no la sentencia de la ira insana de facción victoriosa, tras la lucha sangrienta $\mathrm{e}$ inhumana a que otra igual sucederá mañana...

(Aurora amor. Canto I, 1899)

No lo impulsan las pintorescas narraciones de viajeros, ni un frívolo devaneo, ni la angustia económica de su familia, ni el ansia de traficar con alguna mercancía, ni el destierro impuesto por azares de la política. Su ansia consiste en buscar olvido "a una loca pasión, a una aventura, a un fugitivo sueño" de amor, aunque ello lo obligase a dañar el porvenir del "ángel inocente" que naciera a su calor. Le importa despejar el "porvenir risueño" que se abre a su ambición. No sólo se le antoja liviano y desordenado aquel "fugitivo sueño", sino lesivo a la ventura y la consideración social que debía conquistar merced a su labor tesonera, su previsión metódica y su saber. $Y$ pasan los años. Recuerdo y sombra difusa, es aquel desgarramiento. Con firmeza que nada enturbia, declara ya sus ideales, los "santos ideales" de su posición burguesa:

... Como las flores conservan su perfume si el rocío su cáliz vivifica, he conservado las ilusiones de mi edad primera. 
Los nobles sentimientos, los anhelos de ventura $\sin$ fin, las vaporosas sombras de amor, de luz, de poesía, la ambición de hechos grandes, las coronas, los triunfos y palacios que he soñado en esas horas de candor, aún pasan ante el alma del joven, cuando en noches de soledad y de tristeza llenas me pongo a meditar...

Vive en mí el culto

de las cosas sublimes e inmortales. ¡Jamás la vil profanación del vicio mancillará mis santos ideales!

(Jamás, 1866)

Pero el anunciado culto no se sustenta en el respeto a un valor social específico, ni atiende a un criterio objetivo para atribuir a esos ideales una jerarquía o un grado de pureza. Es el fruto de un proceso mental, muy vago y quizás inconsciente, que infunde al poeta la creencia en la altura de sus propias intelecciones, como resultado de la afinidad contaminante de aquellas "cosas sublimes e inmortales" que ocupan su mente. Pero éstas son tan sólo preseas de su personal desvelo, a las cuales adjudica validez universal con la ilusión de proyectar hacia el mundo sus vivencias y conquistar el respeto debido a quien se halla "sobre el común nivel de los mortales". Amparadas en virtudes austeras, esfuerzo tesonero y amplio saber, en el pensamiento de Luis Benjamín Cisneros apuntan claras tendencias hacia la reivindicación de una función dominante. Aquellos "santos ideales" que pregona tienden únicamente a la satisfacción de sus intereses personales, y no parecen prever las coincidencias que supone una acción en beneficio de la sociedad. $Y$, a despecho de su verbal afecto por las "cosas sublimes e inmortales", es obvio que no le merecen tal valorización sino aquellas que pueden exaltar las manifestaciones de su individualismo. Así, por su esencia y sus proyecciones, el pensamiento y la conducta de Luis Benjamín Cisneros obedecen a las afinidades típicas de la conciencia burguesa. 
Frente a las diferencias que los privilegios establecían entre los hombres, la burguesía apeló a la razón y sustentó los audaces postulados del derecho natural. Pero no bastaba la elaboración de una doctrina que justificase sus ambiciones. $\mathrm{Y}$, con la agudeza corrosiva de su ingenio, Voltaire vinculó el conocimiento teórico de los derechos del hombre a su defensa práctica, y ésta lo llevó a encarar el problema de la libertad política. Libertad, para eliminar las regulaciones feudales y la vigilancia del estado sobre las legítimas actividades de los comerciantes y los empresarios, para asaltar las barreras de los privilegios adquiridos en la cuna, para ocupar en la vida aquella situación prominente que estuviese acorde con la dignidad y la experiencia. Y como la defensa práctica de la libertad implicaba una ruptura del orden tradicional; la burguesía definió también su propio concepto del orden, subordinándolo a la imposición de sus derechos y al consiguiente reajuste de las relaciones sociales. En cuanto alude a la libertad, Luis Benjamín Cisneros ataca, por eso, los desmanes que a su sombra cometieron los caudillos militares, y reclama la paz y la estabilidad sociales que favoreciesen al espíritu de empresa y la sed de lucro:

\footnotetext{
¡Oh! ¿qué es un pueblo libre, si a la orgía se entrega al insultarle los tiranos, sir deja alzarse la ambición sombría y a los hermanos matan los hermanos, si no comprende en su indolencia impía que es el pasto no más de los milanos que entre sí se reparten su tesoro sedientos de poder y ávidos de oro?

¡Perú! Tú ejemplo de naciones fueras, poniendo al crimen y ambición un freno; tienes inmensos bosques y praderas, $y$ oro $\sin$ fin en tu fecundo seno. ¡Oh, nación desgraciada! Ser pudieras edén de dichas y abundancia lleno, cubrir de oro la extensión esférica...

¡Tú puedes ser aún reina de América!...
}

(El pabellón peruano, 1855)

Bien puede alentar en su conciencia el optimismo, al comprobar que el Perú guarda "oro sin fin en (su) profundo seno"; y no 
porque así lo hiciesen concebir la tradición incaica y la codiciosa pasión de los conquistadores, sino porque en oro se había empezado a convertir el prodigioso fertilizante que en las islas del litoral depositan los gituales guanays. Pero duele al poeta que el pueblo no ponga coto a los disturbios caudillescos, e indolente contemple a "los milanos/que entre sí se reparten su tesoro/sedientos de poder y ávidos de oro". $\mathrm{Y}$ añade:

Bien exclamaba un ingenioso vate, al contemplar la inagotable veta:

"Salió por una puerta el pillo Uñate y entró por la otra puerta el sabio Uñeta."

Se dijo: "ipor la Patria se combate!"

$Y$ se engañó a la Patria con tal treta, que al fin y al cabo, inecios de nosotros!, apeados unos, se montaron otros.

(Desconsuelo, 1858)

En verdad, Luis Benjamín Cisneros expresa que el derecho de la fuerza es la raíz suprema del poder económico; y anhela que la fuerza del derecho ampare el desenvolvimiento de la riqueza y coloque a su servicio el poder político. Con dura objetividad, llama "cambio de comparsa" a la renovación que los caudillos introducen en los organismos del gobierno, califica las elecciones como "grandes farsas", y al infecundo recurso de los golpes caudillistas opone la obediencia a la ley. Desalentado y pesaroso, evoca ltuego la cruenta lucha que en cierta ocasión contemplara desde una "alta torre" de Lima, los "gritos de muerte y libertad" que el pueblo lanzaba entusiasmado al conocer la derrota del gobernante a quien llamaba tirano, y la turbulenta conversión del soberano en bandolero:

Cuando aquel mismo sol se hubo ocultado,

al pueblo noble, generoso y fiero,

se le vió en un instante transformado

de rey y soberano, en bandolero.

$\mathrm{Y}$ saqueaba la tienda del culpado

lo mismo que la casa del sincero,

y a los vencidos sin piedad befaba

y por placer, riendo, asesinaba.

(Desconsuelo, 1858) 
Tal inestabilidad afecta la concepción burguesa de la vida, pues implica una constante amenaza contra la propiedad, favorece la consagración de la audacia y el merodeo en los lugares correspondientes a la previsión y el esfuerzo, y, concitando la indolencia y la pasiva lamentación de los ciudadanos virtuosos, lleva a la clausura de aquel porvenir airoso que soñaran los patriotas bajo la inspiración de las "luces". Ya lo dice Luis Benjamín Cisneros:

Fué inútil todo afán, todo trabajo.

Fué inútil tanto "muera" y tanto "viva".

$\mathrm{Y}$ todo el que gritó "truhán abajo", gritaba sin cesar "truhán arriba".

Es la Patria cual india a quien se trajo

de rabona un soldado; nunca esquiva

al golpe que le asesta la canalla, ama con humildad, soporta y calla.

(Desconsuelo, 1858)

$Y$ dice bien. Una vez, tras otra, los caudillos rebeldes imponen cupos en dinero y requisan efectos mercantiles y agrícolas, prometiendo pagarlos desde el gobierno; y, en consecuencia, todo asalto al poder del Estado ejerce un efecto retardario sobre la incipiente economía y debilita el espíritu de empresa. Escéptico ya, el pueblo desahoga sus iras elementales a la sombra de cada revuelta, y no sólo saquea las casas de los hombres a quienes su dedo señala como enemigos, sino las tiendas de inermes e inculpables comerciantes. Una voz de alarma, una algarada popular, o un ligero choque de armas, provocan el precautorio y tradicional cierrapuertas. La ciudad, que el trabajo debía movilizar febrilmente, en rumbo hacia el progreso, queda silenciosa y amortecida. $\mathrm{Y}$ en ese espectáculo no identifican los burgueses la imagen que ellos habían atribuído a la libertad. Por eso aguza el poeta su sensibilidad y, en un lírico desborde, así afloran los consejos que ella dicta:

¡Oh América, patria mía, maldice a esos hijos vanos que colocan en tus manos el puñal de la anarquía!

$\mathrm{X}$ si ha de resonar siempre en tu seno el cañón, si siempre en tu corazón la discordia se ha de alzar; 


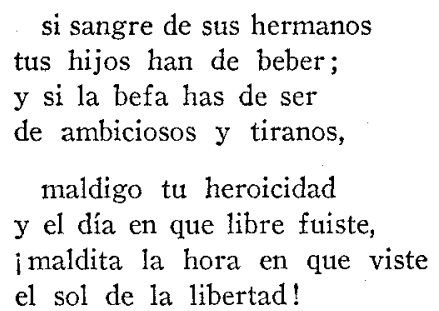

(El pabellón peruano, 1855)

Dondequiera, es ésta la reacción burguesa frente a una realidad que no se acomoda a sus intereses o sus cálculos. Ante su conciencia, la entronización de la libertad en la vida de los pueblos tuvo por objeto quebrar las trabas que coartaron el desarrollo de las iniciativas industriales y del comercio, y facilitar a cada hombre la voluntaria selección de su tarea. Pero, alcanzados aquellos puntos, empezó a demostrar su incomprensión de las aspiraciones planteadas por las capas inferiores de la población, obligando a recordar la incomprensión que la nobleza parasitaria opuso, en su tiempo, a las aspiraciones y las demandas de la burguesía. Así como aquélla apeló al ejercicio absoluto del poder, para frenar su tramonto, la burguesía no halla otro remedio que la dictadura para sofocar el descontento o superar las crisis de crecimiento y reajuste. $\mathrm{Y}$ cuando Luis Benjamín Cisneros lanza su sentimental condenación contra los desórdenes políticos de América - "imaldita la hora en que viste / el sol de la libertad!"- debe entenderse que ya incomoda a la burguesía el régimen liberal, y que las alteraciones de la vida política y social revelan una episódica lucha entre las facciones burguesas que alternativamente pugnan por establecer la dictadura o la libertad.

$$
\text { * * * * }
$$

Paciente y metódica, laboriosa y tenaz, la burguesía hubo de negar y combatir la concepción cristiana de la vida, durante aquella dilatada era en que su actividad comercial y su espíritu de empresa permitieron la comunicación y el intercambio entre oriente y occidente, la superación de la débil economía agraria que hizo languidecer a Europa desde las invasiones bárbaras, y la magnífica aventura que lanzó al hombre hacia el descubrimiento de nuevos 
mundos. Tímida y recatadamente primero, y después sin embozo, el burgués mantuvo una seria discrepancia con las doctrinas que los clérigos intentaban aplicar a la explicación de la vida. La buena o la mala fortuna no podía ser resultado de la prueba que la divinidad quisiese hacer con las virtudes humanas, para discernir luego el premio o el castigo, pues ya era evidente que la inteligencia y el celo personales eran medios aptos para la elevación del rango más humilde. $\mathrm{Ni}$ podía ser exacto que la divinidad reservaba a cada hombre un destino, adscribiéndolo a los poderosos o los humildes, a los ahitos o los necesitados, porque el trabajo y la sobriedad, el orden y la previsión sofocaban en su origen los azares adversos y labraban una decorosa posición, que no figuraba en el esquema social de los clérigos. Instruídos éstos en el acatamiento y la exégesis de los textos religiosos, parecían insensibles a los cambios experimentados por las relaciones sociales y eran incapaces de abandonar una posición conservadora. Comerciantes y empresarios se mantenían ajenos a las implicaciones de tal actitud. Pero los representantes del pensamiento burgués abandonaron la concepción cristiana de la vida y dieron forma a una nueva visión, según la cual es el hombre la medida y el norte de los juicios y los actos posibles. Y si, a despecho de los privilegios amparados por los brahmanes, la prédica budista sustentó la igualdad de los hombres, en tanto que todos son iguales ante las enfermedades y el dolor, la vejez y la muerte; así hallamos en su tiempo a la burguesía tachando las artificiosas regulaciones del feudalismo y sosteniendo bizarramente el principio de la igualdad de los hombres en atención a su común naturaleza. Si la temblorosa y fraterna palabra de Cristo pretendió levantar el ánimo de su pueblo oprimido y esclareció la influencia igualitaria de la filiación divina, así llegaron los pensadores burgueses a sustentar la estructura jurídica de un estado soberano que en nada recordaba a la "Ciudad de Dios" prevista por Agustín de Hipona, $\mathrm{y}$ defendieron la independencia del poder temporal y el poder espiritual, así como la igualdad de derechos de todos los hombres que se hallasen bajo la jurisdicción del mismo Estado. De allí el énfasis que puso la gran revolución burguesa de 1789, al proclamar que "los hombres nacen libres e iguales", satisfaciendo así la aspiración de las capas demográficas que integraban el tercer estado, y resolviendo mediante un postulado jurídico la vieja rencilla con la nobleza y el clero. 
Pues bien, Luis Benjamín Cisneros se muestra heredero de la euforia que inspiró la Declaración de los Derechos del Hombre y del Ciudadano, y desde sus primeros versos evoca los resultados que alcanzó la revolución emancipadora, en cuanto respecta a la igualdad:

$$
\text { ... No la humilla }
$$

el odioso poder de armas extrañas, y arraigada se encuentra la semilla de la igualdad humana en sus entrañas.

(El pabellón peruano, 1855 )

- dice, refiriéndose a América. $Y$ su palabra traduce un generoso entusiasmo cuando comprueba que esa semilla no ha eliminado la opresión, ni la injusticia, ni la miseria. Al lado de la igualdad, y como su corolario, reclama la fraternidad:

Sé que en el mundo el proletario gime, que cada rey, para su pueblo padre, reina inconsciente con la ley que oprime y el pan de Dios no es para todos, madre: la que a los pobres del dolor redime, ley de amor e igualdad, aunque mal cuadre a los que la odian con pavor profundo, quiero que reine iluminando el mundo.

(De mi álbum intimo, 1858)

Pero aún vibra en sus labios la emoción de esta demanda, y ya cree discreto reservarla para las efusiones de su intimidad. Sobre los caminos del mundo caen muchas veces las hojas secas, entregando a los vientos su esperanzada verdura. Y Luis Benjamín Cisneros recuerda alguna vez las limitaciones de aquella igualdad cuya frustración supo ver : en verdad, no había beneficiado a los esclavos nacidos antes de la independencia, ni a los indios, sobre quienes pesó durante largos años un ominoso tributo personal; y el tráfico humano fué autorizado por la constitución de 1839. Recuerda que fué necesaria la cruenta revolución liberal de 1854, para imponer la abolición legal de esas lacras. Pero su visión es puramente consoladora. Se refiere a una etapa cancelada hacía casi medio siglo, y sin ardor, sin justeza ya, olvidando los fundamentos de derecho natural que inspiraron la defensa de la igualdad humana: 
Mancha oprobiosa de la edad cristiana, que a la mitad del siglo subsistía, de inicua y vil esclavitud humana el mundo de Colón tráfico hacía.

Pero pudo, después, el alma ufana, gritar, triunfante tras de guerra impia, de pie ante el orbe, entre ardorosos bravos:

"iNueva gloria a la cruz! iYa no hay esclavos!"

(Al terminar el siglo. XIX, 1900)

En verdad, Montesquieu y otros representantes del pensamiento burgués han planteado el problema de la igualdad como una derivación del ejercicio de la libertad $y$, en consecuencia, han ignorado sus dificultades prácticas, su fisonomía peculiar y la independencia de sus proyecciones. La igualdad se les ha presentado en función de los derechos civiles, como ruptura de los privilegios de casta y alcance de una calidad señorial susceptible de convertir a cada hombre en par de los mayores. Por eso Luis Benjamín Cisneros pone énfasis en su condición de hombre libre, y en su altivez, cuando canta la muerte de un rey:

Yo siento en mí que es digno

de la altivez de tu alma y de la mía,

al través de los mares,

desde apartada tierra

que formó parte de la España un día,

enviarte, cual corona

de flores que crecieron

en el verjel de americana zona,

canto de un hombre libre, esta elegía,

tributo de dolor y simpatía

a la alta majestad de tu personà.

(A la muerte del rey don Alfonso XII, 1886)

Pausadamente se rehabilita el dualismo que en la sociedad reflejaban los antagónicos símbolos de las doctrinas: luz y tinieblas, alegría y tristeza, premio y castigo, abundancia y escasez, riqueza y miseria. El burgués acepta la ideología religiosa que otrora combatiera su previsión y su rebelde pugnacidad y, paso a paso, adopta la filosofía moral de los privilegiados a quienes desplazó. Porque la resignación aconsejada a los pobres armoniza con su idea del orden; 
porque las razones teológicas favorecen ahora su posición, en cuanto explican los favores de la fortuna como favores otorgados a los escogidos de Dios; y porque su vanidad queda profundamente halagada, en cuanto los clérigos le confieren la administración de la providencia, al invitarlo a mitigar la miseria de los otros con las migajas de su banquete. Ya lo dice Luis Benjamín Cisneros:

Gloria y fortuna he anhelado;

pero Dios sabe que no

por egoísmo menguado...

i Si hubo hombre que haya aspirado

a hacer el bien, he sido yo!

Con profundo desconsuelo, lamentando moriré no me haya otorgado el cielo saciar el inmenso anhelo de hacer el bien que soñé.

(Carta a mi difunto amigo Juan Vicente Camacho, 1891)

Es profunda y realmente sincero. El burgués desea otorgar su apoyo al desvalido y socorrer al necesitado. Pero desea hacerlo descie su altura, sin aproximarse a la vida ascética de Cristo. Y, como los privilegiados de otros tiempos, cree que la providencia ha decretado la existencia de los pobres a fin de probar la fortaleza de su espíritu y permitir la acción generosa de los ricos. Por eso halla en la caridad el medio de hacer el bien. $Y$ considera que al hacerla ejecuta un designio providencial:

Cuando llega el pobre anciano

desvalido a nuestra puerta

y pongo en su mano yerta

la limosna que le doy, yo no sé, madre querida, por qué mi alma se estremece

$y$ del cielo me parece

que he venido $\mathrm{y}$ ángel soy.

(La madre... y la hija, 1888)

Fuera de su conciencia se halla la estimación de la eficacia que el acto caritativo pudiera tener en el remedio de la necesidad. Le interesa su propio desprendimiento, cuantioso o mezquino, porque 
infunde en su ánimo la satisfacción del deber cumplido. E inclusive piensa que la limosna deberá renovarse cuando es pequeña, y así es posible llevar al pobre la noción de que se le asiste continuadamente y su necesidad no es olvidada por la providencia: Tiene en cuenta la sabiduría del adagio según el cual la gota de agua labra la roca, e ingenuamente imagina que aún la más insignificante limosna enjuga una lágrima del abundante raudal que no cesa de verter el necesitado. Piensa, lógicamente, que nadie está impedido de practicar la caridad, y puede prodigarla en forma ostentosa, para que los remisos imiten el ejemplo y logre difundirse entre los pobres el consuelo y la esperanza. Por eso halaga al poeta la confidencia de su tierna hija, quien no olvida hacer alguna limosna cuando disfruta de sus propinas:

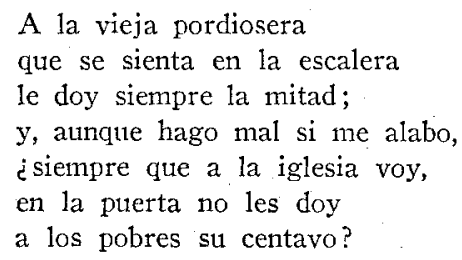

(El collar, 1878)

Este concepto que orienta la conducta individual del burgués, rige también su pensamiento en cuanto afecta a los problemas sociales. Aunque éstos revistan gravedad y hondura excepcionales, los considera inherentes a los módulos de la vida privada y a los caracteres tradicionales de la sociedad misma. $\mathrm{Y}$ si no percibe cómo cambian de calidad los problemas cuando afectan a muchos individuos, se comprende por qué no confía su solución al Estado. Si los considera anejos a la existencia de la sociedad, se comprende por qué no intenta darles solución definitiva. Su mayor esfuerzo se propone únicamente concurrir al alivio de males, cuyo origen y perpetuación atribuye en su mente a la flaqueza del hombre. $Y$ bien lo expresa Luis Benjamín Cisneros, cuando exalta los progresos de su siglo:

De infortunio en las horas inclementes ¿ cuál siglo mostró más, ante el quebranto de gentes propias o de extrañas gentes, de caridad el sentimiento santo? 
¿Cuál creó más asilos de indigentes, enjugó de más huérfanos el llanto, y de la guerra en la azarosa suerte redimió más heridos de la muerte?

(Al terminar el siglo XIX, 1900)

En tan sucinta visión de los problemas sociales asoman, como sus fases más notorias, la miseria, la orfandad y la muerte. El burgués les ha enfrentado la conmiseración piadosa y la caridad, aquellas panaceas que aplica también a los dolores singulares. $Y$ el poeta exclama:

¿Que "fué siglo sin' fe"? ¡Frase mentida! Si el hombre en él venciendo sus errores se sintió de los hombres más hermano, ¿quién osará negar que fué cristiano?

(Al terminar el siglo XIX, 1900)

Su pensamiento reduce la fraternidad a la compasión cristiana, arrebatándole su implícita protesta contra los desplantes de la aristocracia de sangre. Reduce la igualdad al simple goce de ciertos derechos más o menos abstractos, y pretende subsanar los desniveles subsistentes mediante una voluntaria y engañosa caridad. Su sentido práctico y su individualismo le impiden evolucionar hacia una clara y definitiva concepción de la justicia social. Y como cree en la estabilidad de las instituciones y las formas de vida que disfrutaba, no puede reconocer la energía realizadora de los ideales que propician la igualdad y la fraternidad.

\section{Alberto Tauro}

$$
\mathrm{N} O \mathrm{~T} A
$$

* Luis Benjamín Cisneros (1837-1904) nació en Lima. Estudió en el Convictorio de San Carlos. El presidente Ramón Castilla lo incorporó en 1855 al Ministerio de Relaciones Exteriores, demostrándole así el aprecio que le mereciera la alegoría escénica titulada El pabellón peruano. Pero hubo de renunciar al cabo de tres años. $\mathrm{Y}$ en 1859 viajó a París, donde siguió cursos voluntarios en la Sorbona y el Colegio de Francia. En 1861 fué nombrado cónsul en el Havre, y, salvo un interludio durante el cual actuó como 
secretario de la legación acreditada ante el gobierno de España (1865), permaneció en ese puerto hasta 1872. Regresó entonces a la ciudad natal. Desempeñó durante varios años la Inspección de Instrucción y la gerencia de importantes empresas bancarias y comerciales. Pero la Guerra del Pacífico cortó la prosperidad de estas empresas. Luis Benjamín Cisneros viajó nuevamente a Europa, con el objeto de intervenir en su liquidación, y en los adversos azares de la fortuna halló energía para reincidir en sus trabajos literarios. Más tarde ganó nuevo vuelo su inspiración, cuando el cuerpo se doblegó (1888), agobiado por la parálisis; y su frente fué acariciada por la corona de laurel (1897), en la consagración pública que promovió José Santos Chocano.

En el presente ensayo se exponen puntualmente las manifestaciones de su pensamiento, en cuanto afectan a la concepción general del mundo y al lema - Libertad, Igualdad, Fraternidad- que hizo universal la Revolución francesa de 1789. El autor se propone estudiar también sus ideas acerca del gobierno, la misión civilizadora del comercio y la creación literaria. 